\title{
Comparison of the enamel surface roughness before bonding and after debonding by diamond, tungsten carbide and fiber reinforced composite burs under AFM an in- vitro study
}

\author{
Davis T Danny ${ }^{1, *}$, Sugareddy ${ }^{2}$, Srinivas Reddy ${ }^{3}$ \\ ${ }^{\mathbf{1}}$ Assistant Professor, Dept. of Orthodontics, Sree Mookambika Institute of Dental Sciences, Tamil Nadu, ${ }^{\mathbf{2}, 3}$ Professor, Dept. of \\ Orthodontics, Navodaya Dental College, Raichur, Karnataka, India \\ *Corresponding Author: Davis T Danny \\ Email: davisthomasdanny@gmail.com
}

\begin{abstract}
Introduction: The bonding of orthodontic attachments directly to etched enamel surface is an example of clinical application of a simplified procedure. With modifications of the acid etch technique and resin systems, the removal of the directly bonded attachments and finishing of the underlying enamel have become an acute clinical problem.

Aims and Objectives: To evaluate the enamel surface roughness observed under atomic force microscope (AFM) in following methods: 1. Before bonding; 2. Removal of residual resin after debonding with 3 different burs

a. Fine diamond bur

b. Tungsten carbide bur

c. Fiber reinforced composite bur

Materials and Methods: Sixty premolar teeth were divided into 3 equal groups and the buccal surface were subjected to AFM to obtain Ra, Rq, Rmax initial roughness values. The brackets were bonded with a light-cured adhesive and debonded with posterior debonding plier. Residual resin was removed with different burs in 3 groups respectively and subjected to final AFM measurements. Results of roughness were analysed with the use of repeated measurement analysis of variance and independent $t-$ test respectively.

Results: It was found out that parametric values were statistically insignificant with $\mathrm{P}$ value $>0.001$ in prebond condition $\&$ statistically significant after resin removal with $\mathrm{P}$ value $<0.001$. Thereby showing reduced surface roughness regard to fiber reinforced composite, diamond \& tungsten carbide bur respectively.

Conclusion: Fiber reinforced composite bur created smoother surface after debonding when compared to diamond and tungsten carbide bur.
\end{abstract}

Keyword: Fine diamond bur, Tungsten carbide bur, Fiber reinforced composite bur, Residual resin, AFM.

\section{Introduction}

The trend in orthodontics, as in other spheres of human activity is to simplify technical procedures so the objectives can be achieved with a minimum effort. The bonding of orthodontic attachments directly to etched enamel surface is an example of clinical application of a simplified procedure.

With modifications of the acid etching and improvement of physical and mechanical properties of the resin systems, the removal of directly bonded attachments and finishing of the underlying enamel has become an acute clinical problem. Previous major consideration was retention of bonded attachments, now emphasis has recently shifted to the debonding of attachments and the removal of residual resins from the tooth surfaces. A smooth enamel surface after the removal of bracket from tooth is essential for both aesthetic demands and prevention of plaque accumulation.

Even though recent innovations are present in debonding bracket and residual resin removal, but still the commonly preferred method is to use a suitable bur in conjunction with a polishing disc and subsequently a polishing paste. A new composite bur, reinforced by zircon-rich glass fiber, was initially designed to gently remove cement, stains, and coloured coatings from the surface of the enamel. ${ }^{1}$ After resin removal, evaluation of the smoothness of enamel surfaces via scanning electron microscopy (SEM) photomicrographs was unreliable and subjective. Because the surfaces cannot be quantitatively evaluated with SEM, this method cannot be used for comparative assessment of enamel roughness. This has led to a 3D analysis with Atomic force microscopy that offered several advantages that enabled to counterfeit the pros encountered with SEM.

\section{Materials and Methods}

Eighty freshly extracted premolar teeth for orthodontic purpose was collected from the Department of Oral surgery of Navodaya Dental College \& Hospital. Teeth was taken separately and cleaned to remove blood, debris and periodontal fibres from root portion and washed with distilled water. Then it was stored in glass containers containing distilled water. Frequently once in every week distilled water was changed from the glass container containing extracted premolar teeth.

Selection of sample teeth was primarily based on visual examination of the buccal surface of the teeth. Apart from those, inclusion criteria include freshly extracted premolar teeth whether it is maxillary or mandibular for orthodontic purpose. The exclusion 
criteria was caries tooth, fractured tooth or fracture occurred during orthodontic extraction, hypoplastic tooth, teeth with fluorosis, abraded teeth, enamel cracks, enamel crazing and malformed teeth. Finally sixty premolar teeth were selected fulfilling the above mentioned criteria's.

The root portion of the sample tooth was removed at the cervical region uniformly to maintain a flat surface rather getting a sloped surface with the help of carborudum disc. Once disking is done, tooth was placed on a flat surface and checked whether occlusal surface of the tooth was parallel to the flat surface \& even on the horizontal table of the trimmer in order to reduce the thickness of the tooth bucco-lingually (from palatal surface) thereby maintaining a thickness of 3$5 \mathrm{~mm}$ for the crown when measured from the buccal surface.

Prepared samples were transferred to plastic zipper bags containing distilled water for the purpose of transportation without causing any surface contamination to Department of Nano Science \& Engineering, Indian Institute Of Science, Bangalore in order to facilitate the scanning of buccal surface of the teeth under Atomic force microscope before bonding. The surface roughness in the middle one-third of the teeth will be noted. This will serve as the baseline for the comparative evaluation of the study in the further course.

Atomic force microscope (Bruker's Dimension icon with ScanAsyst) was operated in the contact mode first to obtain topographic images over selected areas on the surface. This instrument was supported with a scanner with maximum range of $125 \mu \mathrm{m} \times 125 \mu \mathrm{m} \times 5 \mu \mathrm{m}$ in $\mathrm{x}, \mathrm{y}, \mathrm{z}$ directions respectively. To measure roughness values, the tip was moved across the surface and three different points were measured on the same surface as bonding and debonding of the bracket is mainly concentrated. The measurements involved three roughness parameters expressed in nanometers: Average roughness $(\mathrm{Ra})$ value: the arithmetic mean of the height of peaks and depth of valleys from a mean line, Root mean square roughness (Rq): the height distribution relative to the mean line, Maximum roughness depth (Rmax): value that represents isolated profile features. Before starting the scanning procedure, the whole sample teeth were randomly divided into three Groups (Group A, B, C) containing 20 teeth each.

Crown portions of the sample teeth were embedded in dental stone with buccal surface of the teeth facing uppermost. The dental stone were made in form of small blocks with the samples placed at the middle of the block. Sixty sample teeth which were divided into 3 groups were placed accordingly in a table and were marked separately as Group A, Group B, Group C.

The mounted teeth which were kept separately into three groups were etched for 30 seconds with 37\% Ortho-phosphoric acid (Orthofix, Anabond Stedman, India) and were thoroughly rinsed with water and air dried with oil free compressed air. Adhesive resin (Orthofix, Anabond Stedman, India) was placed on the premolar bracket bases (Stainless Steel Libralmbt 0.022 Slot), brackets were bonded to the prepared enamel surface, excessive adhesive was removed and resin was light cured (3M ESPE ELIPAR ${ }^{\mathrm{TM}}$ ) for 30 seconds. All samples were stored in distilled water at room temperature for 24 hours and brackets were debonded with a posterior debonding plier. The tips of the twin beaked plier were placed against the mesial and distal edges of the bracket wings and squeezed the bracket wing mesio-distally and lift off the bracket with a pull force.

The three experimental group having 20 sample teeth which was coded as Group A, Group B, Group C, the residual resin was removed using three different methods; fine diamond bur (DIA BURS), tungsten carbide bur (G-701 SS WHITE), fiber reinforced composite bur (SHOFU GERMANY) operating using a low speed hand piece $(10,000 \mathrm{rpm})$ and water coolant respectively. The complete removal of the remnant was verified by visual inspection under a dental operating light. The sample teeth were separated from the mounted dental stone without causing any damage to the teeth and were stored in three separate glass container containing distil water.

Samples were transported in three separate zipped bags containing distil water to the Institute to facilitate the scanning process \& final measurements were duly recorded. Data for roughness values was statistically evaluated by repeated measurement analysis of variance for each resin removal method.

\section{Results}

Scanned readings before bonding and after debonding were analysed and duly recorded for three roughness parameters $\mathrm{Ra}, \mathrm{Rq}, \mathrm{Rmax}$.

Descriptive statistics for $\mathrm{Ra}, \mathrm{Rq}, \mathrm{Rmax}$ for three different groups in prebond condition and after resin removal found a statistically significant $P$ value $<0.001$ after resin removal (Table 1). There was a reduced surface roughness in Group $\mathrm{C}$ then followed by Group A, Group B.

ANOVA for Ra, Rq, Rmax between groups and within groups in prebond condition and after resin removal was done, it was found out that in between the groups was statistically significant with $P$ value $<0.001$ than to within the groups after resin removal (Table 2), while in prebond condition it was found to be statistically insignificant.

Multiple comparisons of $\mathrm{Ra}, \mathrm{Rq}, \mathrm{Rmax}$ among three different groups using Tukey's HSD Post Hoc test after resin removal was done, it was found out that statistically significant values were obtained when Group C with B, Group C with A were compared with $P$ value $<0.001$ (Table 3 ). There was a reduced surface roughness in Group $\mathrm{C}$ then followed by Group A, Group B. 
Table 1: Descriptive statistics

\begin{tabular}{|c|c|c|c|c|c|}
\hline Variable & Group & $\mathbf{N}$ & Mean & Std. Deviation & P-value \\
\hline \multirow{3}{*}{ Ra - Post B } & CB & 20 & 21.973 & 7.4740 & \multirow{3}{*}{$<0.001$} \\
\cline { 2 - 5 } & TC & 20 & 48.473 & 11.2240 & \\
\cline { 2 - 5 } & DB & 20 & 43.440 & 12.2550 & \\
\cline { 2 - 5 } & Total & 60 & 37.962 & 15.5142 & \\
\hline \multirow{3}{*}{ Rq - Post B } & CB & 20 & 27.940 & 8.4848 & \multirow{3}{*}{$<0.001$} \\
\cline { 2 - 5 } & TC & 20 & 61.253 & 13.5817 & \\
\cline { 2 - 5 } & DB & 20 & 57.027 & 17.5008 & \\
\cline { 2 - 5 } & Total & 60 & 48.740 & 20.0831 & \\
\hline & CB & 20 & 177.667 & 30.6213 & \multirow{3}{*}{$<0.001$} \\
\cline { 2 - 5 } & TC & 20 & 390.800 & 87.6822 & \\
\cline { 2 - 5 } & DB & 20 & 332.267 & 115.0506 & \\
\cline { 2 - 5 } & Total & 60 & 300.244 & 123.3841 & \\
\hline
\end{tabular}

Table 2: Analysis of variance (Anova)

\begin{tabular}{|c|c|c|c|c|c|c|}
\hline Variable & \multicolumn{2}{|c|}{ Sum of squares } & df & Mean square & F-value & P-value \\
\hline \multirow{3}{*}{ Ra - Post $\mathbf{B}$} & Between Groups & 5942.011 & 2 & 2971.006 & 26.845 & $<0.001$ \\
\cline { 2 - 8 } & Within Groups & 4648.335 & 42 & 110.675 & & \\
\cline { 2 - 8 } & Total & 10590.346 & 44 & & & \\
\hline \multirow{3}{*}{ Rq - Post $\mathbf{B}$} & Between Groups & 9868.385 & 2 & 4934.193 & 26.305 & $<0.001$ \\
\hline & Within Groups & 7878.243 & 42 & 187.577 & & \\
\cline { 2 - 8 } & Total & 17746.628 & 44 & & & \\
\hline \multirow{3}{*}{ Rmax - Post $\mathbf{B}$} & Between Groups & 363765.644 & 2 & 181882.822 & 24.958 & $<0.001$ \\
\cline { 2 - 8 } & Within Groups & 306074.667 & 42 & 7287.492 & & \\
\cline { 2 - 8 } & Total & 669840.311 & 44 & & & \\
\hline
\end{tabular}

Table 3: Tukey HSD post HOC tests for multiple comparisons

\begin{tabular}{|l|c|c|c|c|}
\hline Variable & \multicolumn{2}{|c|}{ Group } & Mean difference & P-value \\
\hline \multirow{3}{*}{ Ra - Post $\mathbf{B}$} & \multirow{2}{*}{ CB } & TC & -26.50 & $<0.001$ \\
\cline { 2 - 5 } & & DB & -21.47 & $<0.001$ \\
\hline \multirow{3}{*}{ Rq - Post $\mathbf{R}$} & TC & DB & 5.03 & 0.397 \\
\hline \multirow{3}{*}{ Rmax - Post $\mathbf{R}_{\mathbf{x}}$} & CB & TC & -33.31 & $<0.001$ \\
\cline { 2 - 5 } & TC & DB & -29.09 & $<0.001$ \\
\cline { 2 - 5 } & CB & DB & 4.23 & 0.677 \\
\cline { 2 - 5 } & TC & DB & -213.13 & $<0.001$ \\
\hline
\end{tabular}

\section{Discussion}

Technological advancements in the field of material sciences necessitate various laboratory testing procedures before a material is cleared and introduced commercially into clinical practice. Most of the orthodontic adhesives are tested for bond strength and biocompatibility in vitro, as there are ethical and clinical issues involved with testing these materials in vivo.

AFM technology was introduced by Gerd Binnig \& Christoph Gerber and commercially available since 1989. AFM uses the method of feeling the surface with mechanical probe which is capable of producing a $3 \mathrm{D}$ image of the sample henceforth smaller the tip, higher the resolution of the image. ${ }^{2}$
Laser irradiation of dental enamel causes thermally induced changes within the enamel to a depth of 10$20 \mu \mathrm{m}$ based on the type of laser and energy applied. Von Fraunhofer et $\mathrm{al}^{3}$ concluded that acceptable shear bond strength could be achieved at laser power settings of $1-3 \mathrm{~W}$, but not at the lowest setting $(80 \mathrm{~mJ})$. This is preferable from the practitioners stand point as the optimum bonding system is one that results in sufficient bond strength to retain the bracket during active orthodontic tooth movement.

Commonly used debonding techniques are debonding pliers, hand scalers, green rubber wheels and assorted rotary attachments. Automatic hand pieces and ultrasonic debonding techniques have been briefly studied were some showing loss \& no loss of enamel during debonding. ${ }^{4-11}$ Fitzpatrik et $\mathrm{al}^{12}$ have reported 
during orthodontic bracket removal, the enamel loss averaged $55.6 \mu \mathrm{m}$. Since the total thickness of the enamel is 1500 to $2000 \mu \mathrm{m}$, the loss of $60 \mu \mathrm{m}$ of enamel is not normally thought to be detrimental.

The bracket debonding procedure should ideally preserve the integrity of the enamel layer. Debonding results in irreversible damage to the enamel (Eminkahyagil et $\mathrm{al}^{13}$ ), ranging from 30 to $60 \mathrm{~mm}$ of enamel loss (Thompson and Way, ${ }^{14}$ Bishara and Fehr ${ }^{15}$ ). An orthodontic adhesive that leaves less or no adhesive remnant is highly preferable in terms of minimizing irreversible damage to the enamel. Bennet ${ }^{16}$ found that squeezing the wings of bracket with plier transferred less stress to the enamel. Electro-thermal debracketing was developed as an alternative for conventional bracket removal method ${ }^{17}$. In this method the heat is transferred to bracket that softens the adhesive allowing the bracket to be gently lifted from enamel surface. But this method can cause adverse pulpal response.

Bishara et al ${ }^{18}$ showed that enamel loss as a result of orthodontic bracket removal is minimized by debonding with the bracket removal pliers followed by ultrasonic removal of the residual composite. Roleau et $\mathrm{al}^{4}$ showed that hand scaler is not desirable for removal of resin because it produces deep gouges compared to 12 fluted tungsten carbide burs.

Other methods like low-speed handpiece with tungsten carbide bur, high-speed handpiece with diamond bur has not left virgin tooth surface with its perikymata intact. Van Waes et $\mathrm{al}^{19}$ \& Campbell $^{20}$ found that there was a limited loss of enamel when tungsten carbide burs were used cautiously. Reisner et $\mathrm{al}^{21} \&$ Kim et $\mathrm{al}^{22}$ concluded that Sandblasting does not appear to damage the enamel surface and therefore be used as a substitute for polishing with pumice.

The cutting efficiency of rotary instruments may be determined by a number of parameters including the rotation speed, pressure applied to the hand piece during cutting, type of bur and flow rate of coolant through the hand piece at the bur/tooth cutting interface was highlighted by Fraunhofer et al. ${ }^{23}$

Burs in high speed rotary instruments usually rotate in a clockwise direction generate a rotational force at the tooth surface thereby the operator must create opposing force to carry the instrument against the tooth surface to get abraded. ${ }^{24}$

For bur to initiate cutting, it must be sharp and should have higher hardness than the material being cut. Knoop hardness values of enamel, fine diamond, tungsten carbide, composite bur is $341,7000,1900,360$ $\mathrm{kg} / \mathrm{mm}^{2}$ respectively. Henceforth diamond bur is less subjected to wear during cutting procedure than the other two burs. Comparatively the roughness caused to the enamel surface will be very less with composite bur considering its hardness value. ${ }^{25}$

Removal of tooth structure with diamond burs results from brittle fracture occurring as the rotated diamond chip creates a groove. With this mode, dislocation motion adjacent to the bur causes an outward flow of material towards the edge of the groove. Hence plastic strain accumulation is limited and large tensile stresses are generated in the near surface region, resulting in crack initiation. ${ }^{23}$

Cutting with tungsten carbide bur is primarily by plastic flow and flow dependent fracture processes due to the high shear forces between the blades and surface. These forces result in plastic ploughing of surface followed by brittle fracture adjacent to the furrows. ${ }^{26}$ The 16 flute carbide bur produces a smoother finish than 8 flute carbide bur, but the latter removes material more rapidly that's the cutting efficiency.

Composite burs have no blade; they act by grinding layer after layer. During abrasion, their fibers divide into fragments and resin matrix is ruined, revealing a new section of glass fibers as self-sharpening feature. ${ }^{27}$ Residual resin removal with composite bur resulted in a decrease in surface irregularities compared to other two burs.

Fitzpatrick et $\mathrm{al}^{12}$ in an SEM study of the effects of acid etching and resin removal on human enamel showed that tungsten carbide bur at high speed removed an average of 55 microns of surface enamel. This was in agreement with studies done by Retief \& Denys, ${ }^{9}$ Campbell, ${ }^{20}$ Hong \& Lew, ${ }^{28}$ Bertrand Marshall and Cooley. ${ }^{4}$ But studies by Zachrisson and Arthun, ${ }^{8}$ Hannah and Smith $^{29}$ and Ingrid et $\mathrm{al}^{30}$ found that tungsten carbide bur at low speed were most effective $\&$ as gold standard for residual resin removal.

Retief \& Denys ${ }^{9}$ recommend air cooling whereas Campbell ${ }^{20} \&$ Rouleau et $a l,{ }^{4}$ Torun et $\mathrm{al}^{31}$ insisted on water cooling. In this study water cooling was preferred with high-speed hand-piece, even though it has the disadvantage of masking the resin remaining on the enamel surface making it difficult for the operator to differentiate between the resin and enamel.

\section{Conclusion}

Summarising the whole by single point or a statement is judgemental, rather than summing up by gatherings results, opinions and decisions made throughout the study. In this study tungsten carbide, fine diamond \& fiber reinforced composite bur were used to remove the residual resin from enamel surface.

Descriptive statistics for $\mathrm{Ra}, \mathrm{Rq}, \mathrm{Rmax}$ for three different groups showed a statistically significant value only after resin removal with a reduced roughness in accordance to fiber reinforced composite bur (Group C) then followed by fine diamond bur (Group A), 8 fluted tungsten carbide bur (Group B) respectively.

Since this is not a pioneering study, but still it's too premature to give a final verdict on certain aspects such as any deflection in hardness of tooth surface (enamel $\&$ dentine surface) in accordance to before bonding and after residual resin removal, any reference to calories of heat generated while using a rotary instrument \& its 
effect on tooth surface which is more efficiently controlled either by air coolant or water coolant procedure. Controversies regarding time factor involved in either single step among each bur or multistep method of polishing systems for removing residual resin in-order to restore the enamel surface to anatomical clinical structure are a relevant aspect in orthodontics to be investigated intensively rather than preserving a perfect orthodontic occlusion after active treatment with plaque or caries prone un-aesthetic teeth.

\section{References}

1. http://www.stainbuster.com. Accessed January 2010.

2. Goodis HE, Marshall GW, White JM, Gee L, Hornberger B, Marshall SJ. Storage effects on dentin permeability and shear bond strengths. Dent Mater. 1993;9:79-84.

3. von Fraunhofer JA, Allen DJ, Orbell GM. Laser etching of enamel for direct bonding. Angle

Orthod. 1993;63(1):73-76.

4. Rouleau BD, Marshall GW, Cooley RO. Enamel surface evaluations after clinical treatment and removal of orthodontic brackets. Am J Orthod. 1982;81:423-426.

5. Pus MD, Way DC. Enamel loss due to orthodontic bonding with filled and unfilled resins using various clean-up techniques. Am J Orthod. 1980;77:269-283.

6. Brown CRL, Way DC. Enamel loss during orthodontic bonding and subsequent loss during removal of filled and unfilled adhesives. Am J Orthod. 1978;74:663-671.

7. Gwinnett AJ, Gorelick L. Microscopic evaluation of enamel after debonding: clinical application. Am J Orthod. 1977;71:651-665.

8. Zachrisson BU, Arthur J. Enamel surface appearance after various debonding techniques. Am J Orthod. 1979;75:121-137.

9. Relief DH, Denys FR. Finishing of enamel surfaces after debonding of orthodontic attachments. Angle Orthod. 1979;49:1-10.

10. Gait C. Use of an automatic handpiece for debonding of composite resin. Eur J Orthod. 1984;6:254-256.

11. Jordan RD, Krell KV, Aquilino SA, Denehy GE, Svare $\mathrm{CW}$, Thayer KE, Williams VD. Removal of acid-etched fixed partial dentures with modified ultrasonic scaler tips. J Am Dent Assoc. 1986;112:505-507.

12. Fitzpatrick DA, Way DC. The effects of wear, acid etchings, and bond removal on human enamel. Am J Orthod. 1977;72(6):671-681.

13. Eminkahyagil N, Arman A, Çetinşahin A, Karabulut E. Effect of resin-removal methods on enamel and shear bond strength of rebonded brackets. Angle Orthodontist. 2006;76:314-321.

14. Thompson RE, Way DC. Enamel loss due to prophylaxis and multiple bonding/debonding of orthodontic attachments. American Journal of Orthodontics and Dentofacial Orthopedics. 1981;79:282-295.

15. Bishara SE, Fehr DE. Ceramic brackets: something old, something new, a review. Seminars in Orthodontics. 1997;3:178-188.

16. Bennett GS, Shen C, Waldron JM. The effects of debonding on the enamel surface. Journal of clinical orthodontist. 1984;18:330-334.

17. Sheridan JJ, Brawley G, Hastings J. Electrothermal debracketing: part I an in vitro study. Am J Orthod. 1986;89(1):21-27.

18. Krell KV, Courey JM, Bishara SE. Orthodontic bracket removal using conventional and ultrasonic debonding techniques, enamel loss and time requirements. American
Journal of Orthodontics and Dentofacial Orthopedics. 1993;103(3):258-266.

19. Van Waes H, Matter T, Krejci I: Three-dimensional measurement of enamel loss caused by bonding and debonding of orthodontic brackets: Am J Orthod. 1997;112: 666-669.

20. Campbell PM. Enamel surfaces after orthodontic bracket debonding. Angle Orthod. 1995;65(2):103-110.

21. Reisner KR, Levitt HL, Mante F. Enamel preparation for orthodontic bonding: a comparison between the use of a sandblaster and current techniques. Am J Orthod Dentofacial Orthop. 1997;111:366-373.

22. Kim SK, Park WK, Son WS, Ahn HS, Ro JH, Kim YD. Enamel surface evaluation after removal of orthodontic composite remnants by intraoral sandblasting: A 3dimensional surface profilometry study. Am J Orthod Dentofacial Orthop. 2007;132:71-76.

23. Siegel SC, von Fraunhofer JA. Dental cutting with diamond burs: heavy-handed or light touch? Journal of Prosthodontics. 1999;8:3-9.

24. Anusavice KJ. Philips science of dental materials. Miissouri: An imprint of Elsevier; 2011. Figure 13-4, the mechanics of high speed rotary instrumentation; p.359.

25. Anusavice KJ. Philips science of dental materials. Miissouri: An imprint of Elsevier; 2011. Table 13-1, Hardness value of dental materials, tooth structure and abrasives; p.362.

26. Eliades T, Gioka C, Eliades G, Makou M. Enamel surface roughness following debonding using two resin grinding methods. European journal of orthodontics. 2004;26:333338.

27. Karan S, Kircelli BH, Tasdelen B. Enamel surface roughness after debonding: comparison of two different burs. Angle Orthod. 2010;80:1081-1088.

28. Hong YH, Lew KK. Quantitative and qualitative assessment of enamel surface following five composite removal methods after bracket debonding. Eur J Orthod. 1995;17:121-128.

29. Hannah CM, Smith GA. The surface finish of composite restorative material. Br Dent J. 1973;135:483-488.

30. Hosein I, Sherriff M, Ireland AJ. Enamel loss during bonding, debonding, and cleanup with use of a self etching primer. Am J Orthod Dentofacial Orthop. 2004;126:717-724.

31. Ozer T, Basaran G, Kama JD. Surface roughness of the restored enamel after orthodontic treatment. Am J Orthod Dentofacial Orthop. 2010;137:368-374. 